\title{
Kalp Yetersizliği Olan Hastalarda Öz Bakım Davranışlarının Değerlendirilmesi
}

\author{
Evaluation of Self-Care Behaviours of Patients with Heart Failure
}

\author{
Hossein ASGAR POUR*, Serap GÖKÇE**, Dilara KUNTER***, Havva YÖNEM***
}

İletişim/ Correspondence: Hossein ASGAR POUR Adres/ Address: Adnan Menderes Üniversitesi, Aydın Sağlık Yüksekokulu, 09100, Aydın Tel: 02562138866 Fax: 02562124219 E-mail: hasgarpour23@yahoo.com

\begin{abstract}
$\ddot{O} Z$
Amaç: Bu araştırmada kalp yetersizliği olan hastalarda öz-bakım davranışlarının değerlendirilmesi amaçlandl.

Yöntem: Araştırma, tanımlayıcı bir araştırma olarak bir Üniversite Eğitim-Araştırma Hastanesi Kardiyoloji kliniğinde gerçekleşti. Araştırmanın örneklemini kardiyoloji kliniğinde kalp yetersizliği tanıslyla yatmakta olan toplam 66 hasta oluşturdu. Verilerin toplanmasında hasta tanıtıcı bilgi formu ve Avrupa Kalp Yetersizliği Öz Bakım Davranışı Ölçeği-12 kullanildl.

Bulgular: Hastaların yaş ortalaması $67.00 \pm 11,09, \% 62,1$ 'i erkek, \%59.1'inde hipertansiyon ve \%51.5'inde diyabet,

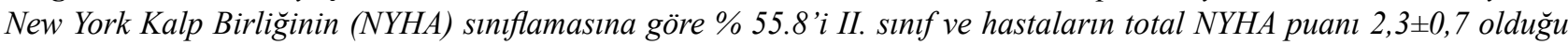

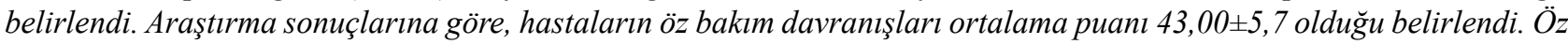
bakım davranışların alt madde değerlendirilmesi sonucu hastaların her gün tartılırım, düzenli egzersiz yaparım ve her sene grip aşısı yaptırırım davranışlarında kısmen yeterli oldukları ve diğer öz bakım davranışlarında yetersiz oldukları saptandı. Ayrıca, cinsiyet ve NYHA sınıflaması ile öz-bakım davranışları arasında istatistiksel olarak anlamlı bir fark bulunmadl $(p>0.05)$.
\end{abstract}

Sonuç: Araştırmamızda hastaların öz bakım davranışlarının yetersiz olduğu belirlendi.

Anahtar Kelimeler: Kalp yetersizliği, öz bakım davranışları.

\section{ABSTRACT}

Aim: The aim of this study was to evaluate the self-care behavior of patients with heart failure.

Method: This descriptive study was realized at the Cardiology Clinic of a University Training and Research Hospital. The research sample consisted of 66 patients hospitalized with a diagnosis of heart failure in cardiology clinic. The data were collected by socio-demographic form, patient follow-up form and The European Heart Failure Self-Care Behaviors Scale-12.

Results: The mean age of the patients was $67.00 \pm 11.09$ and $62.1 \%$ male, 51.5\% for hypertension and $59.1 \%$ diabetes mellitus, 55.8\% in class II according to New York Heart Association (NYHA) Classification and total scores of patients in NYHA classification was determined to be $2.3 \pm 0.7$. According to the results of the study, the average score of patients of self-care behavior was determined to be $43.00 \pm 5.7$. After evaluation of self care behaviours of the subitems was determined to be partially sufficent in behaviors of patients "I weighed every day", "I do regular exercise", "I have flu vaccination every year" and deficient in the other self-care behaviors. In addition, there was no statistically significant difference between sex and self-care behaviors with NYHA classification ( $p>0.05)$.

Conclusion: In our study, it was determined that the self-care behaviors of patients were deficient.

Keywords: Heart failure, self-care behaviors.

*Yrd. Doç. Dr. Adnan Menderes Üniversitesi, Aydın Sağlık Yüksekokulu, **Öğr. Gör. Adnan Menderes Üniversitesi, Aydın Sağlık Yüksekokulu, ***Arş. Gör. Adnan Menderes Üniversitesi, Aydın Sağllk Yüksekokulu

Yazının gönderilme tarihi: 16.10 .2015

Yazının basım için kabul tarihi: 23.05.2016 


\section{GíRiş}

Kalp yetersizliği (KY) tedavideki önemli gelişmelere rağmen morbidite ve mortalite açısından, 65 yaş ve üzerindeki hastalarda en sık hastaneye yatışı gerektiren ve oldukça da uzun bir tedavisi olan önemli bir halk sağlığı problemi olmayı sürdürmektedir (Baydemir, Özdamar, Ünalır 2013; Değertekin ve ark. 2012). KY birey ve ailenin günlük yaşam aktivitelerini sınırlamakta, yaşam kalitesini bozmakta ve aynı zamanda sağlık sistemine büyük ekonomik yük bindirmektedir. Dünya Sağlik Örgütü verilerine göre 2009'da her 1000 yaşl1nın 10'unda kalp yetersizliği bulunmaktadır (Baydemir ve ark. 2013). Yapılan araştırmalara göre Türkiye'de erişkin KY görülme oranı \%2.9-6.9 iken Amerika Birleşik Devletleri'nde KY görülme oranı \%2.2 iken, Türkiye'de ise 2 milyonun üstünde kalp yetersizliği sorunu olan hastanın var olduğu bildirilmektedir (Değertekin ve ark. 2012). KY tedavisindeki temel amaçta yaşam kalitesini ve süresini arttırmak, günlük bakım gereksinimlerini sürdürmesini sağlamak yani hastalığı etkin yönetmektir. Klinik olarak hastalığı etkin yönetmek ve baş etmede başarılı olmak için; hasta eğitimi ve öz-bakım yeteneği geliştirmeyi kapsayan farmakolojik olmayan bir yönetim faydalı olacaktır (Baydemir ve ark. 2013; Özer ve Sezgin 2015).

Öz bakım; bireyin yaşamını, sağlık ve iyiliğini korumak için kendine düşeni yapmasıdır ve bu beceri zamanla iletişim, kültür, eğitim ve etkileşim yoluyla gelişmektedir. Bireyin kendisi ile ilgili aktiviteleri gerçekleştirme yeteneği ise; öz-bakım gücü/yeteneği/etkinliği olarak tanımlanmaktadır. Bireyin öz-bakım gücünü kullanabilmesi için kendine dikkat etme, fiziksel enerjisini kullanma ve kontrol etme, karar verirken özbakım anlayışı içinde yargılama, güdüleme, öz-bakım kararını verme ve uygulama, eylemlerini sıraya koyma ve eylemlerini gerçekleştirmede sürekliliği sağlama gibi bazı özelliklere sahip olması gerekmektedir. Birey, sayılan bu özelliklere sahip olduğu takdirde öz bakım gücü yeterli olmaktadır. Ayrıca, öz bakımını uygulayabilmekte, kendi sağlı̆̆ının sorumluluğunu alabilmekte ve başkalarına bağımlı olmamaktadır. Öz-bakım yönetimi; semptom tanılama, semptomu değerlendirme, tedaviyi uygulama/hayata geçirme, tedaviyi değerlendirme aşamalarından oluşur. Kalp yetersizliğinde öz-bakım; fizyolojik stabiliteyi sağlamak ve semptomlar ortaya çıktığında baş edebilmek için kullanılan doğal bir karar verme sürecidir (Avila ve ark. 2013; Harkness, Heckman, Jewett, McKelvi 2003). Öz-bakım yönetimi kalp yetersizliği semptomları ortaya çıktığında uygulanmakta ve hastalığın etkin yönetimi semptomların kontrol altına alınması sağlamakta; hastaneye tekrar yatışları ve hastalığın ekonomik yükünü azaltmaktadır (Harkness ve ark. 2013; Jaarsma, Arestedt, Martensson, Dracup ve Strömberg 2009; Özer ve Sezgin 2015; Riegel ve Dickson 2008). Hasta kalp yetersizliğiyle ilişkili semptomları tanıma1, semptomun ciddiyetini değerlendirmeli, bununla ilgili bir şey yapmalı ve uyguladığı tedavinin etkili olup olmadığını değerlendirmelidir (Riegel ve Dickson 2008). Yapılan çalışmalarda kalp yetersizliği olan bireylerin semptom yaşadıklarında bu semptoma ilişkin tıbbi yardım aramayı erteledikleri belirtilmiştir. Tedavi aramaya ilişkin bu ertelemenin nedenleri arasında hastaların günlük olarak KY semptomlarını izlememeleri ve yetersizlik oluştuğunda bu durumu erken fark edememeleri gibi nedenlerin olduğu bildirilmiştir (Artinian, Magnan, Sloan ve Lange 2002; Evangelista, Doering ve Dracup 2000; Parshall ve ark. 2001).

European Society of Cardiology (ESC) kılavuzunda belirtildiğine göre KY'de öz bakım, başarılı tedavinin önemli bir parçasıdır ve KY belirtilerinin işlevsel kapasite, genel sağlık durumu, morbidite ve prognoz üzerinde anlamlı bir etkisi vardır. KY tedavisi yaşam boyu sürer. KY'de hastalar karmaşık tedavi rejimlerini yönetebilme, düşük sodyum içerikli diyeti uygulayabilme, düzenli olarak sıvı retansiyonu, nefes darlığı ve yorgunluk gibi erken semptomları izleyebilme ve gerekli girişimleri uygulayabilme gibi öz bakım aktivitelerine uymak zorundadır (Artinian ve ark. 2002; Evangelista ve ark. 2000; Parshall ve ark. 2001). Kalp yetersizliği olan bireylerde öz bakım davranışlarının belirlenmesi ve öz bakım eğitim programlarının uygulanması ve değerlendirilmesi bireylerin yaşam kalitesini olumlu yönde etkilediği düşünülmektedir. 
Araştırma, kalp yetersizliği olan hastalarda öz-bakım davranışlarının değerlendirilmesi amacıyla planlanmıştır.

\section{YÖNTEM}

\section{Araş̧ırmanın Tipi}

$\mathrm{Bu}$ araştırma tanımlayıcı bir çalışma olarak planlanmiştır.

\section{Araştırmanın Evreni ve Örneklemi}

$\mathrm{Bu}$ araştırma bir üniversitenin eğitim-araştırma hastanesi kardiyoloji kliniğinde gerçekleşmiştir. Araştırmanın örneklemini kardiyoloji kliniğinde kalp yetersizliği tanısıyla yatmakta olan toplam 66 hasta oluşturmuştur.

\section{Veri Toplama Araçları}

Veriler ilgili literatür doğrultusunda araştırmacılar tarafindan hazırlanan "Tanıtıcı Bilgi Formu (cinsiyet, yaşı, hastane yatış tarihi, beden kitle indeksi, yandaş hastalıklar, New York Kalp Derneği Kalp (NYHA) Yetersizliği Sınıfı, kalp yetersizliğine dair kullandığı ilaçlar)" ve "Avrupa Kalp Yetersizliği Öz Bakım Davranışı Ölçeği-12” aracılığıyla 20.10.2014-28.05.2015 tarihleri arasında toplanmıştır. Avrupa Kalp Yetersizliği Öz Bakım Davranışı Ölçeği-12 Jaarasma, Stromberg, Martensson ve Dracup (2003) tarafindan kalp yetersizliği olan bireylerde öz bakım davranışları değerlendirmek için geliştirilmiştir. Ölçeğin Türkçe geçerlilik ve güvenirliği Baydemir ve ark. (2013) tarafından yapılmıştır ve iç tutarlı̆g 1 Cronbach alfa katsayıs1 0,69 olarak bulunmuştur. Bu ölçek KY yetersizliğine ilişkin ödem, nefes darlığı, yorgunluk gibi semptomları tanılamayı; bu semptomlara yönelik ilaçların düzenli kullanılmas1, sıv1 ve tuz kisitlamas1, diyet, egzersiz düzenlemesi, sağlik personeliyle iletişim gibi tedavi uygulama ve kilo takibi, ödem takibi gibi öz bakımı değerlendirme aktivitelerini ölçen 12 sorudan oluşmaktadır. Ölçeğin puanlamasında likert tipi ölçek (1-5 arası) kullanılmıştır. Bu ölçekte bölümler "hiç katılmıyorum 5, katılm1yorum 4, kararsızım 3, katıliyorum 2 ve tamamen kat1lıyorum 1" şeklinde puanlanmıştır. Ölçeğin total puanı 12-60 arası değişmekte olup, 12-36 puan öz-bakım davranışın uygun ve 37-60 arası puan öz-bakım davranışın yetersiz olduğunu göstermektedir.

\section{Araştırmanın Etik Yönü}

Araştırmanın yapılabilmesi için Üniversite Tıp Fakültesi Girişimsel Olmayan Etik Kurulundan, Üniversite Eğitim-Araştırma Hastanesi Başhekimliğinden, Kardiyoloji Anabilim Dalı Başkanlığından yazılı izin alınmıştır. Araştırma öncesi hastalara gerekli açıklamalar yapıldıktan sonra sözel ve yazılı izin alınmıştır.

\section{Verilerin Değerlendirilmesi}

Araştırmada elde edilen verilerin analizinde Statistical Package for the Social Sciences (SPSS) for Windows 16.0 paket programı (IBM, Chicago, IL, USA) kullanılmıştır. Hastaların sosyodemografik özellikleri ve diğer faktörlerin değerlendirilmesi için yüzdelik ve ortalama analiz testi kullanılmıştır. Cinsiyet ile özbakım davranışları arasındaki ilişkiyi değerlendirmek için bağımsız t-test ve Kalp yetersizliği sınıfı ile özbakım davranışları arasındaki ilişkiyi değerlendirmek ANOVA kullanılmıştır.

\section{BULGULAR}

Hastaların yaş ortalaması $67.00 \pm 11,09$ olduğu ve $\% 62,1$ 'i erkek olduğu belirlenmiştir. Hastaların beden kitle indeks ortalamas $29.60 \pm 6.34 \mathrm{~kg} / \mathrm{m} 2$ olduğu belirlenmiştir. Yandaş hastalıklara bakıldığında hastaların \% 59.1'inde hipertansiyon ve \%51.5'inde diyabet olduğu saptanmıştır. Hastaların fonksiyonel durumuna göre klinik tablonun NYHA sinıflamasına göre \% 55.8'i kalp yetersizliği II. sınıf ve \% 30.2'sinin III. sınıf olduğu belirlenmiştir. Hastaların tedavi süreçlerinde en çok kullandıkları ilaçların diüretikler (\% 74.2), dijitaller (\% 74.2), beta blokerler (\% 63.6) ve antikoagülanlar (\% 47.0) olduğu belirlenmiştir (Tablo 1).

Tablo 2'de hastaların öz bakım davranışları incelenmiştir. Elde edilen sonuçlar doğrultusunda Öz bakım davranışları ortalama puanı 43,00 $\pm 5,7$ olduğu bulunmuştur. Öz bakım davranışları değişkenlerine bakıld1ğında, davranış değişikliği, sıvı ve tuz kısıtlama, dinlenme, ilaç tedavisine uyum davranışlarında tamamen yetersiz oldukları; semptomlar kötüleştiğinde doktor ve hemşireye haber verme davranışlarında kısmen 
Tablo 1. Hastaların Sosyo-Demografik Özellikleri ve Hastalıklarıyla İlişkin Faktörler-Değişkenler

\begin{tabular}{|c|c|}
\hline \multicolumn{2}{|l|}{ Cinsiyet } \\
\hline Erkek & 62,1 \\
\hline Kadın & 37,9 \\
\hline Yaş Ortalaması & $67,00 \pm 11,09$ \\
\hline \multicolumn{2}{|l|}{ Beden Kitle İndeksi } \\
\hline $16-18.5$ & 3,8 \\
\hline $18.5-25$ & 18,9 \\
\hline $25-30$ & 35,8 \\
\hline $30-35$ & 22,6 \\
\hline $35-40$ & 15,1 \\
\hline$>40$ & 3,8 \\
\hline \multicolumn{2}{|l|}{ Yandaş Hastalıklar } \\
\hline Hipertansiyon & 59,1 \\
\hline Diyabet & 51,5 \\
\hline Kalp iskemi hastalı̆̆ & 40,9 \\
\hline Kalp kapak hastalığı & 16,7 \\
\hline Akciğer hastalı̆̆1 & 16,7 \\
\hline Kardiyomiyopati & 3,0 \\
\hline \multicolumn{2}{|l|}{ NYHA Sınıflaması } \\
\hline I & 9,3 \\
\hline II & 55,8 \\
\hline III & 30,2 \\
\hline IV & 4,7 \\
\hline NYHA Ortalama Puanı & $2,3 \pm 0,7$ \\
\hline \multicolumn{2}{|c|}{ Tedavi Süreçlerinde Aldığı İlaçlar } \\
\hline Diüretikler & 74,2 \\
\hline Dijitaller & 74,2 \\
\hline Beta blokerler & 63,6 \\
\hline Antikoagülanlar & 47,0 \\
\hline Antiplateletler & 36,4 \\
\hline ACE-inhibitörler & 24,2 \\
\hline Antianginaller & 12,1 \\
\hline Angiotensin reseptör blokerler & 9,1 \\
\hline
\end{tabular}

yetersiz ve öz bakımı değerlendirme davranışlarında ise kısmen yeterli oldukları belirlenmiştir.

Tablo 3'te cinsiyet ve NYHA ile öz-bakım davranışları arasındaki ilişki değerlendirilmiştir. Analiz sonuçlarına göre hem erkek hem de kadınlarda öz-bakım davranışları yetersiz bulunmuştur ve kadınlar ile erkekler
Tablo 2. Hastaların Öz Bakım Davranışları Durumu

\begin{tabular}{|l|c|}
\hline Öz Bakım Davranışları Değişkenleri & $\begin{array}{c}\text { Ortalama } \\
\text { Puan }\end{array}$ \\
\hline Her gün tartılırım & 2,95 \\
\hline $\begin{array}{l}\text { Solunum sıkıntım (nefes darlığım) olursa, onu } \\
\text { rahatlatacak şekilde davranırım } \\
\text { (adımlarımı yavaşlatırım, dinlenirim) }\end{array}$ & 4,25 \\
\hline $\begin{array}{l}\text { Solunum sıkıntım (nefes darlığım) artarsa, } \\
\text { doktorumu veya hemşiremi ararım }\end{array}$ & 3,57 \\
\hline $\begin{array}{l}\text { Ayaklarım/bacaklarım normalden fazla şişerse } \\
\text { doktorumu veya hemşiremi ararım }\end{array}$ & 3,52 \\
\hline $\begin{array}{l}\text { Eğer bir hafta içinde iki kilo alırsam } \\
\text { (ağırlaşırsam, kazanırsam), doktorumu veya } \\
\text { hemşiremi ararım }\end{array}$ & 3,06 \\
\hline $\begin{array}{l}\text { I̧çtiğim sıvı miktarını kısıtlarım (günde 1,5-2 } \\
\text { litreden fazla olmamak üzere) }\end{array}$ & 4,00 \\
\hline Gün içinde dinlenirim & 4,52 \\
\hline $\begin{array}{l}\text { Yorgunluğumun artığını hissedersem } \\
\text { doktorumu veya hemşiremi ararım }\end{array}$ & 3,31 \\
\hline Az tuzlu bir diyetle (yiyeceklerle) beslenirim & 4,43 \\
\hline İlaçlarımı önerildiği şekilde alırım & 4,48 \\
\hline Düzenli egzersiz yaparım & 2,67 \\
\hline Her sene grip aşısı yaptırırım & 2,0 \\
\hline Öz Bakım Davranışları Ortalama Puanı & $\mathbf{4 3 , 0 0 \pm 5 , 7 ~}$ \\
\hline
\end{tabular}

arasında öz-bakım davranışları arasında istatistiksel olarak anlamlı bir fark bulunmamıştır ( $\mathrm{p}>0.05)$. NYHA s1nıflarına göre, III. sınıf hastalarda öz-bakım davranışları diğer hasta sınıflarına göre yetersiz ve IV. sınıf hastalarda öz-bakım davranışları diğer hasta sınıflarına göre yeterli olduğu bulunmuştur ancak gruplar arasında istatistiksel olarak anlamlı bir fark bulunmuştur ( $p>0.05$ ).

Tablo 3. Cinsiyet ve NYHA Değişkenler ile Öz-Bakım Davranışları Arasındaki İlişki

\begin{tabular}{|l|c|l|}
\hline Değişkenler & $\begin{array}{c}\text { Öz Bakım Davranışları } \\
\text { Ortalama Puanı }\end{array}$ & p değeri \\
\hline Cinsiyet & $43,36 \pm 1,03$ & 0,535 \\
Erkek & $42,35 \pm 1,09$ & \\
Kadın & & \\
\hline NYHA Sınıfı & $40,66 \pm 1,1$ & 0,109 \\
I & $42,21 \pm 6,1$ & \\
II & $46,72 \pm 6,0$ & \\
III & $38,00 \pm 7,0$ & \\
IV & \multicolumn{2}{|c|}{} \\
\hline
\end{tabular}




\section{TARTIŞMA}

Kalp yetersizliğinde öz bakımın artışı hem yaşam kalitesi artışının bir göstergesi hem de yaşam kalitesini arttıran bir girişimdir. Günümüzde bakım vericiler kalp yetersizliği olan hastaların öz bakım gücünü arttırmaya yönelik uygulamalar yapmaktadır. Bizim araştırmamıza alınan hastalara standart bakım verilmiş ve öz bakım gücünü arttırıcı bir girişim yapılmayan hasta grubundan veri toplanmıştır. Araştırmamıza göre katılımcıların öz bakım davranışının yetersiz olduğu ortaya koyulmuştur. Baydemir ve ark. (2013)'nın çalışmasında KY olan hastaların öz-bakımın yetersiz olduğu belirlenmiştir. Jaarsma ve ark. (2003) yaptıkları araştırmada KY olan hastalarının öz bakım davranış1nın yeterli olduğunu saptamıştır. Sözü geçen araştırma İsviçre, Hollanda ve İtalya gibi ülkelerde yapılmıştır. $\mathrm{Bu}$ ülkelerin sosyoekonomik ve eğitim düzeyi ülkemizden yüksek olduğu için farklı sonuç ortaya çıkabileceği düşünülmektedir. Riegel ve ark. (2009) yaptıkları araştırmada ABD, Avustralya gibi gelişmiş ülkeler ile Meksika ve Tayvan gibi gelişmekte olan ülkelerdeki kalp yetersizliği hastalarının öz bakımı sürdürme ve öz bakım yönetimini karşılaştırmış ve her iki grupta da öz bakımın geliştirilmesi gereken önemli bir konu olduğu ancak gelişmekte olan ülkelerde her iki kriterinde gelişmiş ülkelere göre düşük olduğunu saptamıştır. İran'da yapılan bir araştırmaya göre yine kalp yetersizliği hastalarının öz-bakımı sürdürme ve yönetimi oldukça düşük olarak saptanmıştır (Siabani, Driscoll, Davidson ve Leeder 2014). Harkness ve ark. (2013) araştırmamıza benzer şekilde kalp yetersizliği hastalarının öz bakım yönetiminin düşük olduğunu saptamıştır. Kalp yetersizliği olan hastalarda öz bakım gücü ve yönetiminin düşük olması önemli bir sorundur.

Kalp yetersizliği olan hastaların diyet kontrolü, sıvı kısıtlaması, egzersiz yapma, tuzun azaltılması, ilaç tedavisine uyumu öz-bakım becerisinin arttırılması açısından önemli becerilerdir (Özer ve Sezgin 2015). Araştırmamıza katılan hastaların çoğunluğu öz-bakım davranışlarından solunum sıkıntısı yaşadığında dinlenme, sıvı kısıtlama, gün içinde dinlenme, az tuzlu beslenme ve düzenli ilaç kullanma gibi davranışları gösterdiğini belirtmiştir. Jaarsma ve ark. (2003) çalışmasında ise hastaların çoğunlukla düzenli kilo takibi yapma, düzenli egzersiz yapma ve sorun olduğunda doktor/hemşiresi ile temasa geçme gibi davranışlarda bulunduğunu belirtmektedir. Toplumumuzda kilo kontrolü ve spor yapma alışkanlığg bulunmamaktadır. İki araştırma arasındaki farklılığın yine toplumsal yapı ve kültürel farklılıklardan kaynaklı olduğu düşünülmektedir. Clark ve ark. (2014) yaptıkları sistematik incelemede öz-bakım yetersiz olan KY hastaların genellikle ilaç tedavisine uyum, kilo kontrolü ve düzenli fiziksel aktivite ve sodyumun azaltılması konularında bilgi düzeylerinin düşük olduğu belirtilmektedir.

Araştırmamıza göre NYHA sınıf IV hastaların özbakım davranışları sınıf I hastalara göre daha iyi olduğu saptanmıştır. Baydemir ve ark. (2013) yaptıkları çalışmada katılımcıların büyük bölümü sınıf III ve IV hastalar olup araştırma sonucuna göre hastaların öz-bakım gücü oldukça düşük olarak belirlenmiştir. Riegel ve ark. (2009)'nın yaptıkları araştırmaya göre Avustralya'da araştırmaya katılan kalp yetersizliği hastalarının az bir bölümü (\%20) sınıf III ve IV düzeyinde olup katılımcı dört ülke içinde öz-bakımı sürdürme puanı en yüksek olan grup tur. Bununla birlikte Meksika'dan toplanan verilere göre katılımcıların \%81,4'ü sınıf III ve IV düzeyinde olup yine tüm çalışma içerisinde öz-bakımı sürdürme puanı en düşük olan grup Meksika grubudur. Yine aynı araştırma sonucuna göre NYHA düzeyi öz-bakım inancı için bir belirleyicidir. Literatüre göre kalp yetersizliği hastalarında hastalık şiddetini belirlemek amaciyla NYHA sinıflaması kullanılmaktadır. Bu uluslararası sinıflamaya göre sinıf düzeyi arttıkça kalp yetersizliği derecesi artmakta ve belirtiler kötüleşmektedir. NYHA sınıf I düzeyindeki hastalar günlük yaşam aktiviteleri sırasında sorun yaşamamakta ancak hastalık derecesi arttıkça hasta günlük yaşam aktivitelerini yerine getiremez hale gelmektedir (Badır 2010). Araştırma sonucumuz literatür bilgisi ile uyumludur.

\section{SONUÇ VE ÖNERILER}

Araştırmamızda hastaların öz bakım davranışlarının yetersiz olduğu belirlenmiştir. Araştırma sonuçlarına 


\section{Kalp Yetersizliği Olan Hastalarda Öz Bakım Davranışlarının Değerlendirilmesi}

göre kalp yetersizliği olan bireylerde öz bakım davranışlarının belirlenmesi, eğitim programlarının hazırlanması ve uygulanması, uygulanan eğitim programlarının etkinliğinin değerlendirilmesi ve komplikasyonların erken dönemde fark edilmesi konusunda önem kazanmaktadir.

\section{KAYNAKLAR}

Artinian, N. T, Magnan, M., Sloan, M., Lange, M. P. (2002). Selfcare behaviors among patients with heart failure. Heart \& Lung. The Journal of Acute and Critical Care, 31(3): 161-172.

Avila, C. ve ark. (2013). Cross-cultural adaptation and psychometric testing of the brazilian version of the self-care of heart failure index version 6.2. Nursing Research and Practice, 2013(2013): 1-7.

Badır, A. (2010). Kalp hastalıklarına bağlı komplikasyonlar. Karadakovan, A., Aslan, F. E. (Eds.). Dahili ve Cerrahi Hastalıklarda Bakım. 1. basım, Nobel Kitabevi, Adana, 559-575.

Baydemir, C., Özdamar, K., Ünalır, A. (2013). Validity of the Turkish version of the European Heart Failure Self-Care Behavior Scale. Anadolu Kardiyoloji Dergisi, 13(6): 573-579.

Clark, A. M. ve ark. (2014). Determinants of effective heart failure self-care: A systematic review of patients'and caregivers' perceptions. Heart, 100(9): 716-721.

Değertekin, M. ve ark. (2012). Heart failure prevalence and predictors in Turkey: HAPPY study. Türk Kardiyol Dern Ars, 40(4): 298-308.

Evangelista, L. S., Doering, L. V., Dracup, K. (2000). Usefulness of a history of tobacco and alcohol use in predicting multiple heart failure readmissions among veterans. The American Journal of Cardiology, 86(15): 1339-1342.
Harkness, K., Heckman, G., Jewett, L., McKelvi, R. (2013). Selfcare in heart failure index-Do scores change over time? Canadian Journal of Cardiology, 29(10): 403-404.

Jaarasma, T., Stromberg, A., Martensson, J., Dracup, K. (2003). Development and testing of The European Heart Failure Self-Care Behaviour Scale. The European Journal of Heart Failure, 5(3): 363-370.

Jaarsma, T., Arestedt, K. F., Martensson, J., Dracup, K., Strömberg, A. (2009). The European Heart Failure Self-Care Behaviour Scale revised into a nine-item scale (EHFSCB-9): A reliable and valid international instrument. European Journal of Heart Failure, 11(1): 99-105.

Özer, S., Sezgin, D. (2015). Kalp yetersizliğinde öz bakım. Türk Kardiyoloji Derneği Kalp Yetersizliği Elektronik Haber Bülteni, 7(4):1

Parshall, M. B. ve ark. (2001). Dyspnea duration, distress, and intensity in emergency department visits for heart failure. Heart Lung, 30(1): 47-56.

Riegel, B., Dickson, V. V. (2008). A situation-specific theory of heart failure self-care. Journal of Cardiovascular Nursing, 23(3): 190-196.

Riegel, B. ve ark. (2009). Heart failure self-care in developed and developing countries. Journal of Cardiac Failure, 15(6): 508-516.

Siabani, S., Driscoll, T., Davidson, P. M., Leeder, S. R. (2014). A randomized controlled trial to evaluate an educational strategy involving community health volunteers in improving self-care in patients with chronic heart failure: Rationale, design and methodology. Springer Plus, 3(1): 1-6. 